\title{
INFORMATION TECHNOLOGY IN LANGUAGE TEACHING METHODOLOGY COURSE AT PEDAGOGICAL UNIVERSITY
}

\section{${ }^{\mathrm{a}}$ MYKHAILO RAKHNO, ${ }^{\mathrm{b}} \mathrm{RUSLANA}$ SHRAMKO}

${ }^{a}$ Poltava V. G. Korolenko National Pedagogical University, 2 Ostrohradskyi St., Poltava, Ukraine, 36000

${ }^{b}$ Poltava V. G. Korolenko National Pedagogical University, 2 Ostrohradskyi St., Poltava, Ukraine, 36000

email: ${ }^{a}$ mrakhno@gmail.com, ${ }^{b}$ shramen1atk02006@gmail.com

Abstract: The introduction of information and communications technology (ICT) in pedagogical universities of Ukraine has considerably optimized the professor's preparation for different forms of in-class teaching. The aim of this research is to characterize the range of media resources used during the preparation of the teaching foreign languages methodology course at high-specialized school and universities of Ukraine. The predominant method used to check the effectiveness of ICT was content analysis. The method of psychological experiment served to study the link between ICT and the students' emotional sphere. An anonymous poll has discovered a considerable number of students showing a positive attitude to online instruments and using those resources very frequently or almost every day.

Keywords: foreign language, information and communications technology, media platform, methods, student of a Ukrainian pedagogical university, teaching, tertiary education.

\section{Introduction}

\subsection{The topicality of the research}

The development of digital technology has caused a rapid digitalization of the learning process in the Ukrainian pedagogical universities. Systemic introduction of computerassisted language learning technology in teaching foreign languages for pedagogical university students is the appropriate response to COVID-19 pandemic-related challenges and the need for implementation of distance learning by higher pedagogical education establishments in 2020-2021. Foreign language teachers using a vast spectrum of media instruments provided to support the methodological content have empowered the theoretical groundwork of their courses. Consequently, this has led to the previously developed methodological paradigm itself transforming. Similarly, the technological progress has irrefutably unleashed a new vista of integrating previously purely singular and personal teaching methods into the wider usage, which has raised the quality of the entire field. Using certain elements of information and communications systems to prepare for lectures, seminars, and practical lessons has made the teacher to overhaul the approaches and the structure of their personal preparatory work, with the increased time for professional growth, the reduced psychological pressure and moral burden being other side advantages. On the other hand, studying the methodological component online has allowed a master's degree student, a trainee foreign language teacher, to build their own educational trajectory relying on the transparent "professor - student" subject-subject communication mechanism and providing for personal needs. It is worth mentioning that a certain number of Master's students combine their studies with professional activities in the establishments of general secondary education. The distance learning has contributed to getting the most out of the methodological courses as well as high personal motivation and optimized time consumption, while professional work in the field has allowed the students to practice and hone their skills immediately after their acquirement. Besides, introducing the quarantine and restrictive counter-epidemic measures aimed to prevent the spread of COVID-19 acute respiratory disease caused by SARS-COV-2 coronavirus likewise contributed to creating a suitable educational environment with minimal losses.

The Ukrainian society of the early 21st century views a foreign language teacher in the context of new challenges of our modernity. Where the theoretical base is considered, the teacher is expected to function as a high-level researcher operating the knowledge from pedagogy, psychology, inclusive education, theory of language communication, lingual-cultural studies, neuro- and psycholinguistics, together with learning and teaching principles and strategies. The communicative competence sets the demand for the teacher to be an experienced communicator able to find an individual approach to every student according to the latter's ethnic, social and cultural standards, psychophysiological traits, and educational needs. The educator needs to create a well-meaning and thus favourable atmosphere during the lesson. The expected outcome of this interaction should be voluntary and natural breaking of the psychological barrier by the secondary student, and their introduction to productive cooperation based on deep trust. The level of the methodological training allows qualifying a teacher as a professional tutor and instructor using all instruments and means for enabling the student to understand and internalize the learning material on the basis of stable interest and internal motivation for mastering a foreign language. One of integral constituents of a fully-fledged methodological competence of this professional aiming at mastering a range of "all possible interaction models of phenomena, processes, relations and links within the sphere of teaching foreign languages" (Tarnopolsky, 2020,9 ) is motivated use of digital instruments for productive educational management.

\subsection{Problem stating and analysis of previous studies}

Systematic usage of media instruments in providing the foreign language teaching methodology course contributes to the successful training of Master's students - trainee teachers in the Ukrainian pedagogical universities. That is why the issue of the link between effective educational process time management and information and communications technologies (ICT) is of special importance and topicality in the modern reality. The problem of creating a productive mechanism of combining them for work in bilaterally-oriented dimensions "professor $\leftrightarrow$ student” and "teacher $\leftrightarrow$ pupil” directed at training all language skills, together with the issue of the ICT's place in the life-long personal growth of a professor, a teacher, and a student belong to the sphere of intense interest of the Ukrainian theoretical pedagogues, practical methodology specialists, philologists, and psychologists of the 21st century. For instance, the experience and prospects of using the Internet in learning a foreign language are outlined by Nataliia Nasonova (Nasonova, 2008), the specificity of using multimedia presentations and their potential for teaching a foreign language are specified by Inna Tryhub (Tryhub, 2014), the ICT's role as a component of the innovative training of a modern foreign language teachers is characterized by Vitalii Boychuk, Volodymyr Umanez, Andrii Bezuglyi (Bezuglyi, Boychuk, Umanez, 2018), and Yuliia Rudnik (Rudnik, 2014). The works of Olha Strelnyk (Strelnyk, 2019) and Iryna Kohut (Kohut, 2018) deal with the influence of media technologies on the formation of new professional competences of a foreign language teacher. Liliia Morska (Morska, 2007) likewise Oleg Tarnopolsky and Maryna Kabanova (Tarnopolsky, 2020) set the theoretical groundwork for effective teaching of foreign languages in the Ukrainian environment. Alla Kulichenko and Yurii Polyezhayev (Kulichenko, Polyezhayev, 2020) outline the importance of innovative ICT in teaching foreign languages to students majoring in medicine. The specificity of using certain online instruments in teaching foreign language is described by some overseas scholars, particularly Dafne Gonzalez (2003) and Graham Stanley (2005).

The aim of this research is to locate a range of ICT usable within the framework of the course of foreign language teaching methodology for Master's degree students of the Ukrainian pedagogical universities and to ascertain the effectiveness of these technologies in developing various language skills of trainee foreign language teachers. This aim calls for reaching several goals, the most important ones being showcasing online instruments for working with management and technologies in teaching foreign languages in their synchronic and diachronic cross-section, and also the mechanism of introducing ICT while 
forming the foreign language communicative competence of a higher pedagogical education student

\section{Materials and Methods}

The study is based on the method of content monitoring that, during 2021-2022, enabled the teacher and students in a mixed mode to trace most topical online catalogues and libraries, to pick most popular services for preparing for discussion lectures, seminars, and methodological practical lessons, to select training and testing podcasts, audio-visual materials according to the personal proficiency level in English / German as a foreign language. Using the elements of content monitoring allowed the teacher to use professional online forums, chats, and methodological platforms for sharing the experience of using media services by teachers of the Ukrainian establishments of higher education. For Master's students, using content analysis opened a new prospect of comparative analysis of textbooks and syllabi currently in use in high specialized and higher school of Ukraine and, on the other hand, available authentic teaching materials in the aspect of orientation towards forming the key competences. Besides that, content analysis was essential for Master's students practicing skills of foreign language communicative competence in various types of language use. The introduction of a psychological experiment, more specifically, an online poll and gradual scaling method was implemented after the completion of the course by Master's students, in 2021, in order to locate positive / negative motivation of trainee foreign language teachers for using the ICT potential in their professional activities at the establishments of comprehensive secondary education and to ascertain attitudes of the students to specific media resources while working on the methodology course. The respondents were the philology students (100 persons in total).

\section{Results and Discussions}

Reaching the goals of studying a foreign language and successful internalization of the language are impossible without taking into the account the requirements of the modern scientific knowledge paradigm. Productive mastery of a range of didactic principles and approaches is similarly dependent on topical trends in teaching linguistic disciplines.

Anthropocentrism. For a student, individualizing the education process is the core criterion in choosing both a professional training programme and the higher educational establishment in general. The autonomy of the Ukrainian establishments of higher education offers the prospect of introducing an individual education trajectory and the possibility of adapting the schedule with minimal losses in time and moral resources. The logical outcome of such a personalized approach is the growth in quality of learning achievements. The student's motivation increases and becomes result-oriented. The student-centred nature of the Ukrainian pedagogical universities and their differentiated approach to teaching allows the professor and the student to concentrate their efforts on forming professional (didactic, linguistic, speech, sociocultural, sociolinguistic, literary criticism, comparative, research) competences of the teacher the core of their professiogramme, - efficient usage of which contributes to life-long education.

Information Competence. Exponential growth of data amounts in the early 21st century creates a need for instilling information culture in both the professor and the student. There is an urgent need for improving the readiness and ability of the teacher to select and order materials needed for a specific topic. It is also worth honing the practical skills of using a vast array of technical means of processing the teaching content. Undoubtedly, it calls for personal responsibility and high information competence of a Master's student, a trainee foreign language teacher. Judicial use of ICT both during the introduction stage and the main part of education process can simultaneously simplify and empower communication on the intersubjective level.
Communicative approach. The human-centred focus of the modern scientific knowledge paradigm includes systemic usage of bilateral-oriented subject-subject principle in learning a foreign language when mastering a linguistic structure happens while using this very structure by means of specific language exponents in the communication. By means of ICT, the speaker (professor $\leftrightarrow$ student) can carry out a critical analysis / selfanalysis and correction / self-correction (professor $\rightarrow$ ICT $\leftarrow$ student) of all language skills directly in the framework of the training activity. Combining different forms of work according to the communicative principle with the help of ICT (brainstorming, case technology, the method of problem situation, project work) improves the teaching process's ergonomics ensuring its continuity and reproducibility on each stage. It is ICT that allows to create suitable conditions for these procedures, provided that the professor is sufficiently determined in their preparation.

CLIL, English / German as medium of instruction methods in teaching foreign languages. English as lingua franca, the language of international communication (CEFR, 2020), as well as German play an essential role in training students of the Ukrainian establishments of higher education as an instrument for obtaining knowledge, acquiring skills in other disciplines. That is why getting the students acquainted with these techniques within the teaching methodology course should deepen their professional training and form ability to organize and give lessons of binary, dual and mixed types together with a subject teacher of a secondary education establishment. CLILoriented approach in teaching a foreign language to Master's students of the Ukrainian pedagogical universities provides them with professional terminology empowering the communicative professiogramme and practical professional skills.

English / German for Specific Purposes in the course of foreign language teaching methodology. One of topical modern challenges is the combination of general theoretical facts about the foreign language structure with their specific usage is specialized fields of science. Introducing the module satisfies the requirement for narrow specialists oriented at communicative tasks of a specific field (e.g. EPP: English for Professional Purposes) or an establishment of higher education as a scientific and academic institution (e.g. EAP: English for Academic Purposes). The logical conclusion of this module is a higher level of formation of professional, in particular, linguistic, sociocultural, and sociolinguistic competences of a graduate of higher education establishments of Ukraine, their readiness to work in ambiguous conditions of the ever-changing world. Such a specialist can flexibly use the learned language in its written and oral forms considering its genre and stylistic types, registers of communication, has a sufficient level of ethnocultural / thematic background information, is able to perform situational communication in both the national and international environments, constantly works for the improvement of personal expertise. Thus, it is mostly about the relevance of a highly qualified professional on the Ukrainian labour market of the 21st century.

The course of methodology of foreign language teaching at highspecialized school and university consists of 3 ECTS credits (90 hours), where the teaching and methodological content is grouped in 2 content modules. Each integrates lectures, seminars, and individual methodology practice. At the end of each module students prove their level of obtained knowledge by means of a module test. The final course activity is a complex test work - a defence of an individual methodological portfolio.

Content module 1 "Methodology of teaching foreign languages" integrates the basic information of theoretical and methodological nature within its 3 topics. Every topic of this module starts with a distance Zoom-based lecture. The seminars are provided using the media resource Google Meet enabling the participants of the education process to create a productive online discussion, review and discuss materials prepared by students, send them to the corporate e-mail box of the correspondent department of the pedagogical university. 
Topic 1 "Methodology of Teaching Foreign Languages in the Synchronic and Diachronic Cross-Section” is a problem lecturevisualization using a professor-created Power Point presentation, which shows the mutual connections between the methodology course and other courses of linguistic, literary criticism, and pedagogical cycles. The lecture provides a characteristic of the development of methodology in the historical perspective, modern classifications of didactic principles and approaches, and ascertains leading methods of teaching foreign languages. During the lecture, the professor set discussion points, which were to be brainstormed in mini groups in Zoom waiting rooms with clear timing (2-3 min.). The students were required to design a common optimal solution for such problems as "Trace the connection between the principles of use of visual methods and scientism in teaching a foreign language", "Show the advantages of using a grammar-translation approach in learning English as a Second / Foreign Language", "Motivate using case technology in practicing academic writing skills", "Which method of acquiring the first foreign language is optimal for an extravert student (an introvert)?", “Is it sensible to use brainstorming in practicing a lexical topic with the fifth-year school students? Why?", "Motivate the introduction of synesthetic elements during the beginner stage of teaching a foreign language to first-graders", etc. Having designed the solution, the mini-group participants were to send the answers to the professor in the group chat and consequently to discuss their correctness. The result of Lecture 1 is understanding of concepts "method" and "methodology", forming the skills of critical analysis of each of topical methods on the basis of comparative analysis of their advantages and drawbacks. The preparation of Master's students for the seminar requires completing the following tasks: a) compiling notes on the historical development of foreign language teaching methodology and its connections with other pedagogical, linguistic and literary disciplines using the online resource teachingenglish.org.uk; b) preparing a presentation on the history of a chosen teaching approach in a mini-group of 2-3 participants using padlet.com.

Topic 2 "Management and Technologies in Teaching a Foreign Language" is implemented as a discussion lecture with elements of problem study where the professor presents stages and essence of planning teaching process according to the lesson's aim, the structure of a foreign language lesson in re/productive skills development. A group discussion in the common chat with strict timing for answers has allowed specifying advantages, drawbacks, and functions of CLIL approach in the system of training the modern language teacher in Ukraine. Problem questions such as "Does adapting the teaching content influence the effectiveness of material acquisition during the lesson and why?", "Show the specific features of teaching a foreign language for specific purposes nowadays", "The role of individual professional self-development of a teacher" served as discussion points for the seminar. The core component of the discussion lecture is the review of information and communications technology in teaching a foreign language. Highlighting this aspect is possible through a presentation broadcast in Zoom and showing screenshots of the interface of various internet platforms used for preparing lessons in different types of foreign language competence. The result of Lecture 2 is internalizing the principles of using traditional / unconventional approaches to teaching a foreign language in a combination with different types on online instruments during the learning process. The preparation for the seminar of Lecture 2 requires: a) developing timings for lessons on receptive / productive skills using the resources of esol.britishcouncil.org, iSLCollective.com, esl-lounge.com, eslflow.com belonging to a specific lexical topic; b) a virtual overview of a chosen Ukrainian textbook in foreign language teaching methodology at higher school using padlet.com.

Topic 3 "Functional Approach to the Language and Teaching Language Aspects" as a lecture with problem material presentation shows the ways of forming phonetic / lexical / grammatical competence during which the teacher presents different exercises and activities aimed at improving those competences. Using problem questions such as "Does the work with unique authentic material (proverbs, phraseological and lacunar units) improve the lexical competence of a foreign language teacher?", "Show the relations between practicing different grammar structures and improving grammar competence of the teacher" has focused the students' attention on the importance of the acquirement of solid language skills. The result of Lecture 3 is internalizing the structure and specific features of learning the lexis and grammar of a foreign language. Preparation for the thematic seminar demands: a) creating a folder of authentic texts with unique language material (language clichés, phraseological units, folk riddles, superstitions, omens, lacunar units, etc.) for improving the student's lexical competence. This folder is created, in particular, using online resources tefl.net, busyteacher.org; b) a set of tests for each competence created using the resources of ego4you.com, HotPotatoes, LearningApps.org, etc.

Content module 2 "Forming Foreign Language Communicative Competence" includes 4 topics outlining stages and specific features of language skills and related activities. Each topic offers a lecture and a seminar. The module lectures are organized using the platform Google Meet, while the seminars are Skypebased. Topic 4 "Forming Communicative Competence in Listening» as a discussion lecture covers the following points: methods and principles of teaching listening, types of audio materials and selection criteria on different stages of mastering a foreign language. Problem questions "Comment on the interrelations between listening and speaking skills", "Is it important to adhere to the authenticity principle while teaching listening skills?” discussed by the professor and students in the group chat showed the balance in teaching various foreign language skills. At the end of Lecture 4, Master's students have better understanding of setting up a listening lesson, specificities of using audio content depending on the lesson aim and objectives. The preparation for the seminar includes: a) compiling a set of authentic audio recordings with linguocultural content (clichés, phrasal units, folk riddles, superstitions, omens, lacunar units, etc.) by means of Kahoot!; b) preparing a video fragment (10-15 min.) of a student's lesson in listening skills using OBS Studio software and Audacity audio editor; c) analysis of the level and specific features of the teaching material based on 5 chosen TED-talks recordings from ted.com; d) a presentation of 3 video fragments (5-7 min. each) of favourite films in a foreign language with a self-designed transcript of the characters' speech (using YouTube).

Topic 5 "Forming foreign language communicative competence in reading" as a problem lecture orientates the students to the methods and principles of teaching reading, describes its main types and forms, provides the classification of tasks and criteria for selecting texts for teaching reading. During the online lecture, the following problem questions have been discussed in the collective chat: "Which reading skill/type is aimed at developing research (sociocultural, literary criticism) competence?", "Do innovative, integrated forms of work for improving reading skills (audiobooks performed by famous writers and celebrities, reading promotion by sports stars, etc.) increase the students' interest?". The final part of Lecture 5 is learning the factors influencing the development of students' reading skills and their correction. Preparation for the seminar includes: a) recording a video fragment (10-15 min.) of a reading skills lesson using OBS Studio software; b) creating a text folder (10 samples) of authentic linguocultural content using the web resources gutenberg.org and archive.org for different reading sub-skills; c) preparing one's own translation of 3 text samples (350 words each) of different genres from the web resources gutenberg.org and archive.org, with the usage of ethnicallyspecific units (clichés, phrasal units, folk riddles, superstitions, omens, lacunar units, etc.).

Topic 6 "Forming Foreign Language Competence in Oral Speech" in the form of the discussion lecture aims to show the role and functions of monologue and dialogue speaking in communication, to provide the lesson stages and task types for speaking practice. During the lecture, the following problem questions have been discussed in the group chat: "Interrelation of 
literary language and dialect (national) variant”, “Tasks for Fluency". The final part of Lecture 6 is practicing the mechanism of setting up restricted and freer practice activities during a speaking lesson. Preparing for the seminar integrates a set of tasks: a) recording a video fragment (10-15 min.) of a speaking lesson using OBS Studio software; b) a set of authentic tongue-twisters for practicing the pronunciation of vowels, consonants, distinguishing monophthongs and diphthongs using the platforms eslspeaking.org, iSLcollective.com, esllounge.com, esl-Flow.com; c) creating a set of tasks for practicing free speaking (monologue / dialogue) using the online instruments and resources HotPotatoes, LearningApps.org, Kahoot!, cambridgeenglish.org, etc.; c) analysis of 3 chosen video fragments (5-7 min.) with star TV hosts or politicians (a news set, an interview with a celebrity, a talk show, etc.) with the focus on individual speech features (using the resources of ted.com, YouTube).

Topic 7 "Forming Foreign Language Communicative Competence in Writing" in the format of a presentation lecture shows different types and forms of writing, elucidates factors influencing the development of this competence. An integral lecture component is the chat discussions of the following points: "Are skills of clear formatting of a written message important in the modern epoch of the technical support provided by intellectual information systems?", "Can the modern means of communication substitute human grammar accuracy?” At the end of Lecture 7, the students are better able to differentiate between writing types and sub-skills, to understand their essential components and outline. The seminar preparation includes: a) developing an essay bank (8-10 samples) with different communication aims using the resources of tefl.net, busyteacher.org, teachingenglish.org.uk, esol.britishcouncil.org web-sites; b) presentation of extended (with didactic hand-outs) lesson plans ( 1 - in receptive skills and 1 - in productive skills) based on topics from high school syllabi (FRS, 2017) and using the online instruments found at iSLcollective.com, esllounge.com, esl-Flow.com, Google Docs; c) recording a video fragment (10-15 min.) of a student's own distance lesson in teaching writing using the resource grammarly.com (a screen recording is created using OBS Studio software); d) forming a set of communicative tasks (10-15 samples) for practicing writing skills based on high school topics and using ego4you.com, HotPotatoes, LearningApps.org, etc.; e) presentation of 5-7 samples of e-letters of different types (a letter to a foreign friend, an answer for a formal application letter, an inquiry for detailed information on college/university studies in a country which language is studied) with collective viewing and editing enabled via Google Docs and Padlet.

It is worth mentioning the importance of continuous professional development and digital competence in particular for the specialist during the course of foreign language teaching methodology. One of topical challenges, which arose in the early 21st century, is the professor's ability to be "on the same wavelength" with their students. It mostly has to do with the ability to keep the personal account in social networks (Facebook, Twitter, Instagram, etc.). In the professional plane, one should be able to create a personal blog / a personal mage / an academic repository, fill it with the appropriate content as a portfolio sample, upload it to a certain platform (for instance, using esol.britishcouncil.org); upkeep an effective mail exchange with the representatives of the world professional community for productive sharing and improvement of pedagogical and methodological experience; to register at a professional group website (ORCID, LinkedIn) for self-presentation of personal achievements; to take part in distant seminars, conferences, and professional forums providing high-quality oral and written communication; to practice life-long learning using different courses of professional development at international platforms such as cambridgeenglish.org, iSLcollective.com, esllounge.com, esl-Flow.com, prometheus.org.ua, BBC; to create personal audio/video content for methodological purposes (OBS Studio, Audacity, YouTube); to practice innovative interactive forms of work (method of neurolinguistic programming, brainstorming, problem situations, case technology, linguistic training sessions) in teaching foreign languages. The project activities of both the professor and the student deserve special attention as it requires the ability to do independent research work in the Internet, to select appropriate authentic materials, to work with (cloud) services for creating audio and video recordings, presentations, to discuss the projects and edit them collectively in a professional group. The outcome of such activities is the mutual enrichment with experience and increased teaching quality of each of the participants.

After the completion of the course in foreign language teaching methodology, in order to ascertain the skills of students in the ICT field, an online poll (Figure 1) was offered using the following form:

1. How often do I use online resources in preparing for my learning / teaching activities?

a) almost never;

b) once a week;

c) three times a week;

d) constantly, I do not imagine my preparation without the Internet;

e) your answer.

2. How well can I create a presentation?

a) with great difficulty, I almost never use it;

b) I can create a presentation with the help of my friends or groupmates;

c) easily;

d) I see no need in using presentations in my work;

e) your answer.

3. Do I use authentic materials from different online resources to prepare for different types of my lessons?

a) almost never;

b) rarely, a paper version is preferred;

c) sometimes when there is a real need;

d) constantly, cannot imagine my work without authentic materials;

e) your answer.

4. How often do I use video/audio content to raise my own language proficiency?

a) almost never;

b) rarely, when there is some free time;

c) sometimes, in case of real need;

d) constantly, I cannot imagine my life/work without authentic content;

e) your answer.

5. Do I create / upload my own teaching content in a foreign language to online resources?

a) never;

b) rarely;

c) sometimes;

d) constantly;

e) your answer.

6. What is my attitude to the necessity of having my own page in social networks / on professional platforms / creating my own blog / an e-portfolio, etc.?

a) positive;

b) wary;

d) I see no need in this;

d) negative;

e) your answer. 
Figure 1. Information and Communications Technology in the Course "Methodology of Teaching Foreign Languages at High (Specialized) School and University"

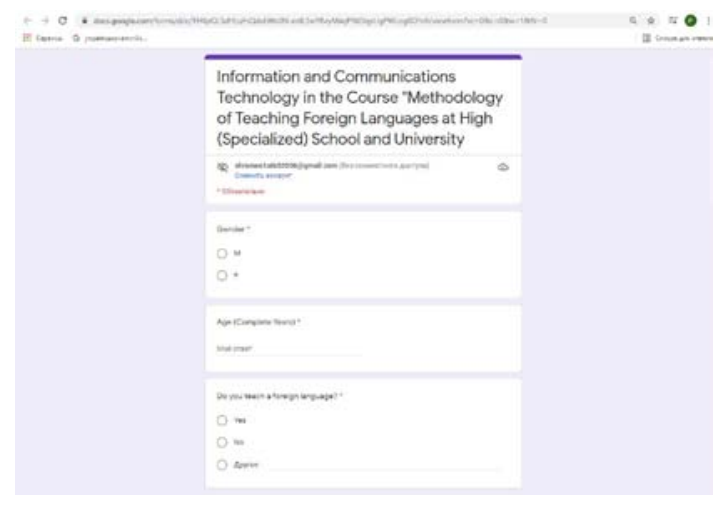

Note: own questionnaire designed specifically for the research

The results of the experiment undertaken show that $78 \%$ of respondents constantly use online instruments for teaching a foreign language (or other subjects), while $22 \%$ of the interviewees try to combine the traditional format of studies (paper-based teaching materials) with media resources. Positive motivation for using Internet resources is found among $84 \%$ of respondents while $16 \%$ are wary about using them. Continuous development of personal language proficiency by means of media content is found among $68 \%$ of the respondents, the rest (32\%) considers using online resources to complete a specific communication task. Only $21 \%$ of respondents are inclined to upload their self-designed materials to online platforms, while $79 \%$ are extremely cautious about that. $90 \%$ of the students participating in the poll have their own social media accounts, which shows their high level of social motivation.

\section{Conclusions}

Using ICT in the course of foreign language teaching methodology is an extremely powerful means of professional development of the teacher and simultaneously a topical instrument of teaching a foreign language at a pedagogical university of the early 21st century. Introducing online resources and platforms allows to plan the learning process more effectively and optimize it at high school and university levels, offers a vast array of techniques for sharing available authentic materials / producing self-designed teaching content, opens numerous prospects for professional development in different activities; it is a strong "bridge" for distance / extramural communication with students. All these factors show the importance of information and communications technology in the professional career of the Ukrainian school and university teacher on the modern labour market.

Thus, the paper does not highlight all the spectrum of the problems but contributes to the issue of interaction between professor and student via ICT in the up-to-date educational process, opening the perspective of its future all-embracing research.

\section{Literature:}

1. Tarnopolsky, O., Kabanova, M.: Methodology of Teaching Foreign Languages at Higher School: a Textbook for Students of Specialized Linguistic Establishments of Higher Education. Vinnytsia: Nova Knyha, 2020. 384 p. ISBN 978-966-382-825-1. 2. Nasonova, N.: Practice and Prospects of Using Computer and Internet Technology in the Learning Process of Teaching a Foreign Language. In: Proceedings of the Sixth International Conference "Internet - Education - Science. IES - 2008", Sec. B. Internet and Informational Technologies in Education, Vinnytsia, Ukraine, October 7-11, 2008. Vinnytsia: UniversumVinnytsia, 2008. pp. 117-119. ISBN 978-966-641-266-2.
3. Tryhub, I.: Multimedia presentation as a perspective direction of foreign languages teaching. Anthropological Studies: Collection of Scientific Works of Ivan Franko Drohobych State Pedagogical University. Issue 29, part 3: Pedagogy. Drohobych: Ivan Franko DSPU, 2014. 274 p. pp. 196-205. ISSN 2313-2094. 4. Bezuglyi, A., Boychuk, M., Umanez, V.: Information and communication technologies as an innovational factor improving training of modern teacher. Modern Information Technologies and Innovation Methodologies of Education in Professional Training: Methodology, Theory, Experience, Problems: Collection of Scientific Papers. Issue 52. KyivVinnytsia: TOV “Planer”, 2018. 465 p. pp. 205-211. ISSN 24121142. ISBN 978-966-2337-01-3.

5. Rudnik, Yu.: Actualization of the Issue of Using Innovative Technology in Teaching Foreign Languages. Modern Teacher Training Issues: A Collection of Scientific Works of Pavlo Tychyna Uman State Pedagogical University. Issue 10, Part 2. Uman: Private Entrepreneur Zhovtyi O. O., 2014. 304 p. pp. 124-132. ISSN 2307-4914.

6. Strelnyk, O.: Facilities of multimedia as component of forming of project competence of philologists. Scientific Journal of M. P. Drahomanov National Pedagogical University. Series 17: Theory and Practice of Education and Upbringing: a Collection of Scientific Works. Issue 30. Kyiv: Publishing House of M. P. Drahomanov NPU, 2019. 220 p. pp. 170-174. ISSN 2519-4623.

7. Kohut, I.: Information competence as a structural component of the professional pedagogical communicative competence of a teacher in the contemporary educational space. Educological Discourse: electronic scientific edition, no. 3-4(22-23). Kyiv: Borys Grinchenko Kyiv University, 2018. https://doi.org/1 0.28925/2312-5829.2018.3-4.3281. ISSN (Online) 2312-5829. 8. Morska, L.: Theoretical and Methodological Foundations of Training a Foreign Language Teacher to Use Information Technology: a Monograph. Ternopil: Volodymyr Hnatiuk TNPU, 2007. 243 p. ISBN 966-7425-77-0.

9. Kulichenko, A., Polyezhayev, Yu.: Innovative information and communication technologies for ergotherapists applied during English learning in Ukraine. AD ALTA: Journal of Interdisciplinary Research. 2020. no. 10(02). pp. 228-233. https://doi.org/10.33543/1002228233.

10. Gonzalez, D.: Teaching and learning through chat: a taxonomy of educational chat for EFL/ESL. Teaching English with Technology, 2003. vol. 3, no. 4, pp. 57-69. Available at: http://www.iatefl.org.pl/call/callnl.htm.

11. Stanley, G.: Blogging for ELT. British Council. Barcelona, 2005. Available at: https://www.teachingenglish.org.uk/ article/blogging-elt.

12. CEFR: Council of Europe. Common European Framework of Reference for Languages: Learning, teaching, assessment: companion volume. Council of Europe Publishing, Strasbourg, 2020. Available at: https://rm.coe.int/common-european-frame work-of-reference-for-languages-learning-teaching/16809ea0d4. 13. FRS: Foreign Language Syllabi for Comprehensive Secondary Schools and Specialized Schools with In-Depth Study of Foreign Languages. Grades 10-11. 2017. Available at: https://mon.gov.ua/storage/app/media/zagalna\%20serednya/prog ramy-10-11-klas/2018-2019/inozemni-movi-10-1119.09.2017.pdf.

Primary Paper Section: A

Secondary Paper Section: AM 